\title{
THE CULTURES OF PHILANTHROPY: PRIVATE FOUNDATION GOVERNANCE IN THE USA, THE UK, GERMANY, AND JAPAN
}

\author{
STEPHEN LEW AND DARIUSZ WÓJCIK
}

\begin{abstract}
This paper explores philanthropic finance by analysing data on the sizes and structures of the 20 highest-giving private foundations in the United States, the United Kingdom, Germany, and Japan in 2005. It is shown that socio-cultural rather than purely economic indicators are better predictors of private foundation giving. Foundations in the four countries show similarities in terms of age, geographic scope, areas of funding and lack of performance measurement. Methods of income generation, asset management, and capital deployment however, differ significantly between countries. We suggest that while philanthropic culture and governance exist, they bear the features of national business culture and governance. Conclusions are drawn for the feasibility of competition and collaboration, as well as the use of performance metrics, among private foundations.
\end{abstract}

\section{INTRODUCTION}

Philanthropy has made headlines in the recent years with a series of historical largescale donations, including Warren Buffett's pledge of some $\$ 37$ billion worth of Berkshire Hathaway shares to the Bill and Melinda Gates Foundation in 2006 (Bishop, 2006) and Sir Thomas Hunter's pledge of some 1 billion pound sterling $(\overline{\mathrm{FT}}, 2009 \mathrm{~b})$. The philanthropy sector in the European Union alone represents some 174 billion euros in terms of asset under management and 46 billion Euros in terms of giving. Moreover, the philanthropy sector, as represented by foundations in the European Union, has seen "dramatic growth" in the last 15 years, where some $43 \%$ of foundations from within 9 member states of the EU having been founded from the year 2002 to 2008 (EFC, 2008b). Closer to events as of 2009, philanthropy continues to thrive despite the credit crisis and depletion of personal wealth by many "ultra high net-worth individuals" and private foundations (Bishop and Green, 2008).

According to the Oxford English Dictionary, the term "philanthropy" is defined as being "the desire to help others, especially through donation of money to good causes." The Greek root of the term, philanthropia, literally, is "love-man" or the "love of mankind". The colloquial usage of the term in English might refer to the practice of middle incomebracket individuals donating relatively small amounts of money (or volunteering their time for a local non-profit organization), billionaires pledging hundreds of million dollars to their eponymous foundations in order to support causes of their choice on the private citizenry level, and corporations and civic organizations setting up charitable foundations to serve their communities. Of many activities that can be said to comprise a nation's "philanthropic" activity, we shall focus on the activities of the private individual putting their wealth to use on behalf of public interest. It is not only closer to the colloquial usage

\footnotetext{
Key words and phrases. economic geography, geography of finance, philanthropy, philanthropic finance, foundations, governance, culture.

OXFORD UNIVERSITY WORKING PAPER IN EMPLOYMENT, WORK AND FINANCE 09-14
} 
of the term and what the term connotes but is also closest to the spirit of charity, i.e. private wealth being put to use for the public good, particularly by the very affluent. Also, of many formats through which this could be executed, we shall focus on the financial or monetary means by which such an activity can be funded, i.e. the philanthropic finance. By this phrase we mean the giving figures of private foundations, rather than the assets which they manage.

The existing literature provides a patched landscape of philanthropic finance, particularly with respect to any comparative analytic work. From the economic geography perspective, despite several initial explorations (Hurd et al., 1998) (Wolpert, 1988), there is little direct research on philanthropy as a whole or its financial aspects. In economics, even some of the more extensive works by economists on philanthropy, on the whole, put great emphasis on creating formal models for altruism, relying heavily on the maximization of utility function perspective, while saying paradoxically little about the sizes, structures, and dynamics of philanthropic finance (Kolm and Ythier, 2006). Philanthropic finance remains a neglected area within the geography of finance literature as well. That being said, the bottom-up approach and some of the key insights afforded by both economic geography and geography of finance provide us with a useful platform upon which to carry out the study. More general works on non-profit organizations and philanthropy also tend to neglect comparative analysis of philanthropic finance; the comparative analyses that do exist tend to focus instead on different historical origins, rather than a comparative analysis of private foundations according to a select features, the methodology employed in our study (Ilchman, 1998) (Cizakca, 2000).

Our objective in this paper is to explore philanthropic finance, as economic geographers, by comparatively analyzing the sizes and structures of philanthropic finance in the US, the UK, Germany, and Japan at the level of private foundations. Through this exploration, in effect, we seek to lay the groundwork for research on 'foundation governance' (or, more generally, 'philanthropic governance'), mirroring that of corporate governance. To this end, we aggregate the giving figures of 20 highest-giving private foundations in each country, and comparatively analyze them according to select features.

The following research questions are asked:

(1) What are the sizes of philanthropic finance, as represented by the giving figures of the 20 highest-giving private foundations, in the UK, US, Germany, and Japan, how do they differ, and what factors have affected this variation?

(2) What are the structures of philanthropic finance in the above countries, in what specific ways do they differ, and what determinants might explain these variations?

The main empirical findings of this paper are as follows. Firstly, there are no significant correlations between private foundation giving and macroeconomic or institutional variables such as the levels of national and individual wealth and taxation rate. Secondly, socio-cultural indices such as wealth inequality, perceptions about civic responsibility in wealth redistribution, and the importance of religion, have significant bearings. Thirdly, there is clustering of both age and headquarter locations of the foundations. Fourthly, there were significant overlaps in the areas of giving both in terms of projects and geographic focus. Fifthly, Anglo-American foundations and the German and Japanese counterparts respectively exhibited aspects that reflected the corporate governance regimes of respective country-pairs, particularly when it came to sources of income, asset management policies, methods of giving, and performance measurement. Thus, the sizes and structures of philanthropic finance are products of complex interactions of economic as well as socio-cultural 
factors, not necessarily something that arise out of well-defined institutions causing explicit top-down causations.

The sections to follow are outlined as the following. In section 2 , we introduce the approaches and key insights drawn from economic geography, geography of finance, and philanthropy literatures that inform our comparative analysis of philanthropic. In section 3 , we discuss the data sources and methodology. In sections 4 and 5, we present empirical results on the sizes and structures of philanthropic finance, answering each research question, respectively. In section 6 , we present conclusions and implications for the theory of private foundation governance.

\section{Towards a Theory of Philanthropic Governance}

This section presents relevant concepts and literatures with respect to the research questions and introduces hypotheses which we might reasonably expect to verify through the empirical analysis. The objective of this paper is to comparatively analyze the sizes and structures of philanthropic finance in the US, the UK, Germany, and Japan at the level of private foundations and what determinants might affect the variations. There are several intellectual platforms upon which to frame such an analysis. Our view is that the approaches and insights afforded by economic geography, including geography of finance, inform the most suitable intellectual framework. Our aim is to approach the comparative analysis of philanthropic finance from economic geography perspective, keeping in mind that philanthropy is an intensely personal enterprise informed by society and culture. As such, the literatures herewith are to be drawn from four related areas: on the one hand, economic geography and geography of finance, and on the other hand, the literatures on non-profit and philanthropy in general and on comparative philanthropy, focusing specifically on comparisons across countries in their philanthropic practices. The section will conclude with a discussion on what precise gap this paper is attempting to address.

The most appropriate intellectual platform upon which to pursue this endeavor is economic geography in its approach and insights. Given the personal and value-driven nature of private foundation philanthropy, it is imperative that the comparative analysis of philanthropic finance in the four countries is approached not purely in economic terms Andreoni and McGuire, 1993) von Kotzebue and Wigger, 2009), but from a more holistic 'bottomup' perspective which includes economic terms and practices. This paper discusses both aspects, seeking traces of a culture of philanthropy that are universal elements across cultures and distinct from a corporate culture, and how these cultures of philanthropy differ across countries. Firstly, in its approach, economic geography supplants the idea of "the economy' as a pure, monolithic, and ethereal entity as well as commitments to formal models based on homo economicus (Coe et al., 2007) with the notion that an economy is a construct informed by society, culture, and politics. As Clark et al (Clark et al., 2003). would state it, the approach "values narrative methods, the pluralism of geography, and the limits of formalism." Secondly, economic geography provides results that are relevant for our purposes: different types of states exist, for example neo-liberal states (e.g. the US and the UK), welfare states (e.g. Germany), developmental states (e.g. Japan); corporations have economic cultures (Sheppard and Barnes, 2002), and such cultures tend to be embedded in the business practice culture and the national culture of their origin, even for multinational firms (Coe et al., 2007).

The geography of finance literature is also relevant for both the 'bottom up' approach as well as the key insights. Of many aspects of philanthropy, our focus in this paper is the financial aspect. Private foundation philanthropy, after all, is a highly finance-intensive 
endeavor, involving fundraising, investing assets for generating return, and funding causes. Results such as the following can elucidate comparative analysis of philanthropic finance: there is greater supply in the boutique asset management industry in the US and the UK than in Germany and Japan (Corbridge et al., 1994); the Anglo-American variety of capitalism has become increasingly 'financialized' and Germany and Japan, in some respects, have followed suit (Martin, 1999); the Anglo-American corporate governance tends to be more 'open' relative to the German and Japanese counterpart, one of the implications of which is that greater transparency is required, which in turn necessitates more active reporting (Clark and Wojcik, 2007). One way of stating the contributions which economic geographers are uniquely situated to make might be the following threefold localization thesis: finance is localized in history (path dependence), in institutions such as fiscal and regulatory environments, and in access to information (Leyshon, 1997). That being said, in the wake of the credit crisis, researchers have argued that the risk originating from one location spreads to another, emphasizing the ways in which geographies are interconnected and interdependent (Clark et al., 2009).

The general literatures on non-profits and philanthropy abound but tend to neglect comparative analysis. Broadly speaking, the most thorough reference work on non-profits (Powell, 2006) and overviews on the current state of philanthropy (Bishop and Green, 2008) (Til, 2008) tend to outline general aspects of philanthropy such as the personal nature of philanthropic giving and the notion that the US has a particularly pronounced culture of giving on the part of the individual (Payton, 2008) (Raymond and Martin, 2007), with the eponymous private foundation as a vehicle of choice (Fleishman, 2007) (Grimm, 2002). Sophisticated quantitative and experimental works have been carried out in the non-profit and philanthropy research, encompassing various methodological strands: simulation on social networks and private philanthropy (Apinunmahakul and Devlin, 2008), experiment showing that a matching offer from a charity organization increases the likelihood of giving from donors (Karlan and List, 2006), and formalistic works with little empirical content that attempt to explain philanthropy from the utility maximization perspective ( $\mathrm{Kolm}$ and Ythier, 2006). None of these work approach philanthropic finance from an economic geography perspective and analyze them according to sets of features at the level of foundations.

Even the literatures that compare philanthropic activities across countries tend to do so in a specific manner that diverges from our approach. Their approach tends to be historical comparisons of philanthropic traditions in different cultures (Ilchman, 1998) (Hasan, 2008) or cross-country comparisons of the aggregate expenditures (Whitman, 2009) (Onishi). Detailed cross-country analyses of philanthropic giving via private foundations are generally reports with various inconsistencies (CAF, 2009), devoid of theoretical dimensions (EFC) 2005) (EFC, 2008b), in-depth analysis or narrative (Dimson, 2007).

Our review of the relevant literatures supports that economic geography, including geography of finance, provides a helpful platform upon which to frame the analysis of philanthropic finance. Their approaches and key insights lend themselves to reasonable hypotheses with respect to philanthropic finance. However, there is a striking lack of comparative work on philanthropic finance in economic geography, particularly in contrast to the abundance of comparative work on corporate governance and varieties of capitalism tradition. Despite a large corpus of literature in existence in regard to non-profits and philanthropy in general including corporate philanthropy, comparative analysis on philanthropic finance remains neglected here as well. The existing comparative work tends to juxtapose largerscale trends (Pharoah, 2008) (Glaeser and Shleifer, 2001) rather than focusing on specific features of individual philanthropic organizations. As such, this paper can be regarded as 
both extending the research on geography of finance through approaching philanthropic finance from a 'bottom up' methodology and applying some of the insights from the field such as corporate governance, transparency, and shareholder structure; in effect it is an exploratory work towards a theory of 'foundation governance'. The paper also fills an important gap in the literature on philanthropic finance as a topic, irrespective of the disciplinary approach, being the first of its kind to analyze philanthropic finance at the level of private foundations according to an array of specific features. Below we present features with which to comparatively analyze philanthropic finance, literatures and concepts relevant to each of them, and the hypotheses.

\subsection{What are the sizes of philanthropic finance, how do they differ, and what}

factors have affected this variation? In order to account for the amount of private foundation giving, it is reasonable to expect the following variables to have an effect: wealth (including the wealth of the country, the amount of giving relative to the national wealth, the amount of giving relative to the individual wealth out of the top income bracket (Pharoah, 2008) ) and institutions (income tax rate and government expenditure on welfare relative to the country's wealth). Philanthropy, after all, is an enterprise of the wealthy, and in the countries under consideration, the money that is allocated to the private foundation is tax exempt. Philanthropy can be interpreted as being a form of activism via monetary means. That is to say, when a country levies taxes, what is implicitly stated is that the taxpayer is obligated to 'outsource' one's public service to the government which will then administer the aggregate fund on the taxpayer's behalf. When the country administers tax incentives for private foundations, it is in effect stating that the taxpayer can do the public service himself.

There are anecdotal and historical evidences to suggest that the US in particular has a long-standing and vibrant philanthropy sector (Fleishman, 2007) (Bishop and Green, 2008). In the Anglo-American media, one encounters the activities of large private foundations such as the Gates Foundation in the US ( $\mathrm{CoP}, 2009)$ and the Children's Investment Fund Foundation (FT, 2009a). Furthermore, through daily living in the Anglo-American context, one frequently encounters the legacies of philanthropic largesse by figures such as Andrew Carnegie, John D. Rockefeller (Brown, 2005), Bill Gates, Henry Wellcome, Lord Nuffield, and so on, through various think tanks, libraries, performing art centers, and universities (Bishop and Green, 2008). Also, studies have demonstrated that the AngloAmerican taxation rates as well as the government expenditures on public welfare are lower (Martin, 1999) and that Germany and Japan have more extensive welfare systems than the Anglo-American counterparts (Dore, 2000). Therefore, we might reasonably expect that the US will lead the group in the amount in giving in absolute terms as well as in terms relative to the national and individual levels of wealth and that the Anglo-American philanthropic finances would correspondingly be larger than that of Germany and Japan.

It would be naive to assume that only wealth and tax breaks would motivate a wealthy individual to set up a private foundation and give. Other factors to take into account include the level of wealth inequality (Atkinson and Piketty, 2007) and culture and perceptions towards wealth redistribution (Berger, 2006) and the individual's role in so doing (WVS, 2009) (Kumar and Thibodeaux, 1998). Research has shown that the Anglo-American culture tends to be more individualistic than the German and Japanese counterpart (Christensen and Levinson, 2003), which values conforming to the social order more highly. Moreover, it cannot be denied that somewhat of a "celebrity culture", individualism taken to the extreme, exists in the Anglo-American context (Hofstede, 2009) (Browne, 2003). Rather than being historical and cultural peculiarities, these aspects have direct impact on the economic behavior of a society (Guiso, 2009) (Laroche, 2009), including philanthropic 
giving (Castro, 2008) (Ross, 1953). In other words, in the US and the UK, a very wealthy individual might not only perceive inequality in wealth distribution more, but also might be inclined to act upon such a perception, plausibly for societal recognition, rather than deferring to authority such as the national government.

Japan provides a strong case in point: as Ilchman et al. (Ilchman, 1998) report, "although Japan is far from a Utopian society, it has done an excellent job in providing health care and other social services and in ensuring a more equitable distribution of wealth." The Gini index of Japan is almost at $10 \%$ of that of the US counterpart (Atkinson, 2008). Cultural aspects are also relevant, particularly with respect to deference to authority and the extent of individualism. As Buckley (Buckley, 2001) observes, for example, Japanese culture as a whole tends to defer to the national government on a variety of issues, including education, health care, and social welfare. As such, "philanthropy in Japan will probably grow at a somewhat modest rate" (Ilchman, 1998). The German culture can be described as being similarly 'socialized', albeit to a lesser extent (Trommsdorff, 1985). In all, we might again reasonably expect that the Anglo-American private foundation giving will be greater than the German and Japanese counterparts.

\subsection{What are the structures of philanthropic finance, in what specific ways do} they differ, and what factors might explain these variations? In accounting for the structure of philanthropic finance, we select an array of features that would capture the essential aspects of our sample of private foundations: when and by whom they were founded, where they are located and in what area and geographical regions they give, how they generate income and manage their assets, and how they give and evaluate performance. In regard to when the foundations were established, there are historical reminders to dictate that wealth creation in the US, the UK, Germany and Japan underwent a peak around the 1890's, post World War II-decades, and the technology bubble in the 1990's (Micklethwait and Wooldridge, 2003) (Atkinson and Piketty, 2007). As the three periods in which the wealth creation peaked in the industrialized countries, we would expect the ages of the foundations to be diverse, peaking primarily around the 1890's, the 1960's and the 1970's, and the late 1990's and the early 2000's. In regard to the founders, it is evident from the philanthropy literature that most of them are entrepreneurs in various sectors (Bishop and Green, 2008), some of them having been instilled the concept of charitable giving from an early age, sometimes as a part of their religious upbringing (Grimm, 2002) (Fleishman, 2007). Therefore, we might expect to find a large overlap in their backgrounds as having been entrepreneurs and possibly brought up in a religious household.

Research has shown that the US and Germany have more even urban hierarchies, e.g. the corporate headquarters of large multinational firms are more evenly spread throughout the respective countries, whereas they tend to be more concentrated in the capital cities in the UK and Japan (Coe et al., 2007). It would thus be reasonable to expect that the locations of the foundations would reflect this distribution. Many US philanthropists started foundations so as to "give back to society", particularly the society in which they created their wealth, implying the hypothesis that the geographic focus of their service would be their local communities (Fleishman, 2007) (Berghahn, 1999). Given the relative abundance of specialized third party asset management institutions in the US and the UK (Clark and Wojcik, 2007), we might expect that the Anglo-American foundations would utilize them for generating income, whereas the German and Japanese foundations might manage their own security portfolios in-house. We might also reasonably expect that the Anglo-American foundations' capital deployment method would resemble their asset management method, i.e. outsourcing to third-party institutions, whereas the German and Japanese foundations would keep tighter control over their projects. 
The Anglo-American corporate governance tends to be more 'open' in contradistinction to the German and Japanese counterparts and the former demands greater transparency in reporting (Clark and Wojcik, 2007). As such, it would be reasonable to expect that the Anglo-American foundations would be more vocal about demanding measurable results and that the German and Japanese foundations would follow suit. From the philanthropy literature as well, the traditional model of "prestige and warm-glow" (Harbaugh, 1998) has been increasingly questioned and a greater call has been made for the utilization of performance metrics (Porter and Kramer, 1999) (Bertelsmann, 2006). The debate centering around the idea that in the for-profit industry, the performance metric is simply the net profit, whereas in the non-profit industry, there is no straightforward counterpart (Lakdawalla and Philipson, 2006) (Flynn, 2002); the possibility or even the desirability of the very idea of performance metric itself is under question (Flynn, 2002). On the one hand, inferring from the critiques in the literature concerning the lack of performance metrics in philanthropy, we would not expect many foundations to make extensive usage of performance metrics compared to the corporate sector.

In summary, by addressing our research questions, we aim to analyze the size and the structure of philanthropic finance in four of the largest economies in the world from several complementary perspectives. Building on the literatures reviewed above and the features we have selected, we might hypothesize that a philanthropic culture might exist that distinct from the corporate culture, but at the same time, that the philanthropic culture of a country might reflect certain aspects of the corporate culture of the country. In so doing, we keep in mind that in neoclassical economics, what constitutes the 'best practice' has often been some form of idealized version of the Anglo-American corporate governance, while in the 'varieties of capitalism' tradition no ideal way of organizing an economy exists and that "corporate governance continues to differ according to the institutional context in which it is embedded" (Clark and Wojcik, 2007). Similar tension may exist in what we might term 'foundation governance' with no assumption that there is 'best way' to organize philanthropy. Before we empirically test our hypotheses, the following section presents data and methods.

\section{Data AND Methods}

In comparison to other financial-related industries, comparable and reliable international data on philanthropic finance seem not to exist. Philanthropy, by the nature of the enterprise, pertains to the transfer of wealth from the wealthy to the less wealthy. At the country level, it would have been ideal to find a consistent and sufficient number of private foundations of 'wealthy' countries such as the 29 member-states of the OECD (or the 27 that have been designated by the World Bank as being wealthy) and comparatively analyze the sizes and structures of their giving. The data sets that are currently available, however, tend to be various reports that purport to illustrate the size, structure, and dynamics of the philanthropic sector in a fairly limited set of countries such as the United States, the United Kingdom, and some member states of the OECD. There are other aspects that hinder meaningful comparative analysis, such as inconsistent definitions with respect to what constitutes a "foundation" from country to country (EFC, 2008a), the voluntary nature of figure-reporting, and the absence of reporting standards (Dimson, 2007). Even the reports that have been compiled do not agree on what variables to report, e.g. the asset size or the amount of giving, whether it should be a list of private, corporate, or community foundations, or a combination of all of them.

Given the situation above, we consulted with Cathy Pharoah's study on family foundation for the bulk of our data set so as to identify the top 20 private foundations according 
to their giving figures in the US, UK, Germany, and Japan. Published in May 2008 by the Centre for Charity Effectiveness, the paper, "for the first time, maps the giving levels of the UK's largest charitable family foundations and provides an international comparison with those in the rest of Europe and the US" (Pharoah, 2008, page 6). In other words, this work provides lists of top 100 private foundations according to their giving figures in the US, UK, and continental Europe, providing along with them some preliminary statistical analyses. The Japanese data was not available in the report, so we relied on a data set published by the Japan Foundation Center (JFC, 2009). Here, the data that is available is not "private foundations" per se but all zaidanhojin, or foundation-backed incorporated entities, which includes not only private foundations but also corporate and community foundations. Using such a data set might seem to dilute the results at a first glance, but it will become clear as to why this is a sensible move in the discussion to follow. Once we have gathered the necessary figures and added them up, we then proceeded to investigate whether they might be correlated with potential determinants, focusing initially on specific macroeconomic variables and progressively moving on to less obvious ones.

For the structure of the 20 highest-giving US foundations, we accessed the Foundation Center website. Concerning the US foundation data, this can be considered to be the best database in terms of its comprehensiveness and accessibility. As for the 20 highest-giving UK foundations, we consulted the Charity Commission of the UK website (CC, 2009). Under the UK charity regulations, every non-profit organization is required to register with this website. For the German data, the European Foundation Centre in Brussels (EFC, 2009) lists summary sheets of certain select foundations, which we consulted. Regarding the Japanese data, there are no centralized databases that aggregate the data. As such, we accessed the website of each foundation, where available, extracting the relevant data. In each of the four countries, in order to obtain data that are more specific to each of the 20 foundations, we consulted the individual website, press releases and coverage, and annual reports of each foundation.

As was remarked earlier, comparative analysis of philanthropic finance across countries at the level of foundations according to specific arrays of features has been absent. Existing literature is limited to reports, country-specific books, and presentations. While our analytical methodology is simple, it addresses a crucial gap, shedding light on the sizes and structures of private foundation giving and providing directions for further research.

\section{Sizes of Philanthropic Finance}

In this section, we shall investigate plausible determinants for creating the variations in philanthropic finance by private foundations. Table 1 summarizes the sizes of philanthropic finance, as defined by the total giving figure of the top 20 foundations in giving figures, in the United States, the United Kingdom, Germany, and Japan. In terms of the absolute giving figure, the ordering of the countries was the US, the UK, Germany, and Japan, with the US being the highest at some $\$ 3.3$ billion, Japan the lowest at $\$ 235$ million, around $7 \%$ of the former. The first plausible determinant for this ordering we consider is wealth, both on the national and individual levels as indicated by the GDP and the aggregate wealth of billionaires, respectively. While the US was the leader in absolute giving figure, the UK leads in giving relative to the GDP as well as the aggregate private wealth of billionaires of each country, $\frac{\text { Giving }}{\text { GDP }}$ and $\frac{\text { Giving }}{\text { Billionaire Wealth }}$, respectively.

The second metric to consider is taxation, particularly how individuals in the top income brackets are taxed and what kind of tax incentives they might receive upon charitable giving, as both are some of the more powerful potential determinants for setting up private 
TABLE 1. Philanthropic Finances in the US, the UK, Germany, and Japan in 2005 (Source: authors' calculations based on data from Family Foundations (Pharoah, 2008), World Bank, Forbes, OECD, and World Values Survey.

\begin{tabular}{|c|c|c|c|c|}
\hline Metric & US & UK & Germany & Japan \\
\hline Total Giving (\$) ${ }^{b}$ & 3,318 & 994 & 501 & 235 \\
\hline$\frac{\text { Giving } \times 1,000}{G D P}(\%)$ & 23 & 46 & 17 & 5 \\
\hline$\frac{G D P i n g}{\text { Billioniare Wealth }}(\%)$ & 0.54 & 3.58 & 0.38 & 0.69 \\
\hline Income Tax Rate (\%) ${ }^{c}$ & $35 ; 10.3]^{d}$ & 40 & 45 & 40 \\
\hline$\frac{\text { Gov Exp on Welfare }}{G D P}(\%)$ & 6.4 & 15.9 & 25.4 & 13.0 \\
\hline Gini Index (\%) & 40.8 & 36.0 & 28.3 & 4.5 \\
\hline Civic Responsibility ${ }^{e}$ & 5.9 & 5.9 & 4.5 & 4.0 \\
\hline Religion Important $(\%)$ f & 47.4 & 21.0 & 11.2 & 6.5 \\
\hline
\end{tabular}

\footnotetext{
${ }^{a}$ Private foundation data on Japan were unavailable. Therefore, we are using the top 20 in giving community/corporate foundations data as proxy indicators for the extent of philanthropic activities in Japan.

${ }^{b}$ Unless otherwise noted, the monetary unit in this study is a million US dollars.

${ }^{c}$ Referring to the top individual income tax rate levied upon the highest income-bracket individuals.

$d$ The federal and the state rates, respectively.

$e$ The survey asked the respondents to rate a given value in a scale of 1 to 10 , where 1 corresponds to 'disagreeing entirely' and 10 to 'agreeing entirely'. The original question was (V118) "Government responsibility"; 1 = The government should take more responsibility, $10=$ People should take more responsibility. To make it more intuitive, i.e. the higher the value, the more in agreement with the title of the question, we changed the title.

$f$ The question was V9-(V9) "Important in life: Religion, Very important, Rather important, Not very important, and Not at all important. Among these, "Very important" is quoted. Related questions such as membership to religious organizations or considering oneself as a religious person showed similar patterns.
}

foundations (Anderson, 2005) (Diamond, 2006). It is reasonable to expect if individual income tax were high, then the government tax revenue and expenditure for public service would presumably be high, and as a result, the giving by private foundations would be low. However, it is evident that the individual income tax rate is not a reliable predictor for philanthropic finance. For example, while the top individual tax rates for the UK and Japan were identical, their philanthropic finances varied significantly in favor of the UK. Another closely related factor is tax incentive, i.e. the tax deduction or credit which the very wealthy could claim by giving to tax-exempt entities or setting up their own private foundations. It is reasonable to expect high tax incentives encouraging high giving (Blumkin and Sadka, 2007). However, tax incentives in the four countries were not markedly different from each other: private foundations in all four countries were exempt from taxation on income generated by administrating their assets, economic activities, and donations (EFC, 2008b). Moreover, individual donors in all four countries were able to claim tax deduction, rather than tax credit, for their donations. Overall, it was arguable whether such differences pose significant motivating factors in terms of giving in the top-income bracket individuals.

The third metric we consider is the distribution of wealth in each country. The government spending on welfare relative to GDP did not necessarily negatively correlate to philanthropic finance. However, wealth inequality, as measured by the Gini index, inversely correlated with it, i.e. the more even the distribution of wealth, the less the size of philanthropic finance, and vice versa. We might hypothesize from this finding that the higher the inequality in wealth in each industrialized country represented herewith, the higher the 
public's perception about the wealth inequality, and that the public might be more inclined to act in an attempt to rectify the situation (Buckley and Croson, 2006). In other words, the more uneven the country's distribution of wealth, the more active the country's private foundation philanthropy is likely to be, providing other factors unaccounted for thus far.

The fourth and final metric we consider is a group of socio-cultural indices. The foregoing discussion motivates a close inspection of indicators pertaining to the citizen's attitude towards wealth accumulation, distribution of wealth, and the government's role in so doing. Quantitative measurements of such indicators can be compiled from sources such as the the World Values Survey (WVS, 2009). The values indicated in the table in each category corresponds to the average of the responses. A clear division was observed between the Anglo-American attitude towards civic responsibility and the German and Japanese counterpart. That is, the former pair saw it as the people's responsibility to bring about social changes, whereas the latter pair deferred to the government for such tasks. These variations in attitudes, in part, explain the sizes of philanthropic finance in the US and Japan. Attitudes towards religion displayed a similar division. This is significant in that not only most religions admonish charitable giving, but also in the practical dimension in that significant portions of some of the largest private foundations are focused on faithspecific causes and organizations (Gruber and Hungerman, 2007) (McCleary and Barro, 2006).

The discussion thus far pertained to the sizes of philanthropic finance in the four countries. In the discussion, we observed that there were no straightforward causal links between the country's philanthropic finance and various macroeconomic variables. However, we were able to observe that some correlations existed between the size of philanthropic finance and specific perceptions and attitudes towards society, particularly in regard to the level of wealth inequality and the extent to which citizens defer to their government in redistributing wealth. This calls into question the larger socio-cultural contexts that give rise to such practices, perceptions, and attitudes. This, in turn, necessitates a mesoscopic analysis, i.e. to look more closely at the backgrounds and practices of each private foundation that give rise to the more macroscopic variations in philanthropic finance.

\section{Structures of Philanthropic Finance}

This section comparatively examines the top 20 foundations in giving figures in the US, UK, Germany, and Japan, following the features introduced in the preceding section. Table 2 summarizes the results.

5.1. Founding Year and Age. As much of the modern philanthropy began with the industrial age or the era of "robber barons" in the United States in the 1890's (Fleishman, 2007) (Gaudiani, 2003), it would be reasonable to expect that the average age of the US private foundation would be older than those of the other countries; for that matter, it would also be reasonable to expect to find their founding years being biased towards, on average, the late 1990's, coinciding with the technology boom. Surprisingly however, the average founding year corresponds to the 1960's, i.e. neither the 1890 's ${ }^{1}$ nor the 1990 's, with the oldest founding year being the year 1925 and the most recent, the year 2001. The dispersion is uneven as well, the US ages are more evenly spread, followed by the UK and Germany, and the Japanese foundations having been founded more closely to each other in terms of founding years. In fact, it is remarkable that the Japanese foundations are as old as they are. As a historical matter, for over 5 years after the ending of World War II, the US General Douglas MacArthur ruled Japan (Caiger, 1997). In this period, MacArthur 
forbade founding of any civil societies so as to mitigate the risks of them being used for front organizations for far right militarist or communist organizations (Tadashi, 1999).

In total, the most 'generous' (that are not necessarily the wealthiest) of the private foundations in the four countries have post-World War II roots. The war decimated the wealth of the four nations, closing a chapter in philanthropy in all four countries. However, the extent of the destruction was not uniform, with more pronounced effects on Germany and Japan than on the US and the UK. We note that the more extensive the WWII destruction, the younger the private foundations are. We might hypothesize that the young entrepreneurs who witnessed the buildup to, the progress of, and the aftermath of the war might have felt the need to rectify the social injustices that they would have witnessed. By the time that they amassed enough wealth to create their own private foundations, some 20-25 years might have passed, corresponding to the average founding years of the foundations on our list in each country.

5.2. Founder's Background. The industrial, national, cultural, and religious backgrounds of the founders are also pertinent. The founders were revealed to be mostly entrepreneurs who founded and ran their own companies, accumulating extraordinary wealth. Apart from this commonality, however, there seem to be little correlation between industries and the areas that the foundations support (e.g. the entrepreneur that created his wealth in the news media industry supporting literacy) or whether certain industries necessarily give rise to the founding of the foundations. In regard to the religious affiliations of the founders, the American and British founders who stated their religions, were of Christian and Jewish orientations. ${ }^{2}$ There was virtually no mention of religious affiliations on the part of any of the founders in Germany and Japan. When it was mentioned, as was the case with several German foundations, it was to deny any religious affiliations. While most founders were the citizens of the countries in which the foundations are registered, not all of them were, e.g. Sir Henry Wellcome, who was a US citizen.

The founder's background in the context of philanthropy via private foundations is highly significant. It is such background that determines the values that are dear to the founder's heart, and value systems are highly influenced by one's upbringing, religiosity, and the local and national cultures (Prewitt, 2006) (Dowie, 2002). As Walter Hewlett, the Chairman of the Board of Trustees of the William and Flora Hewlett Foundation revealed, in a private foundation context, what, whom, where, and how it funds are entirely up to the discretion of the foundation's governance. This indeed is one of the key strengths of the private foundation, as the founders do not need to be answerable to shareholders or voters. Such discretion, in turn, will be determined by their values, which in turn are determined by the personal backgrounds, much of them shaped by culture (Fleishman, 2007).

5.3. Locations of Headquarters and Branches. The headquarters of the US private foundations were concentrated in the following states: Pennsylvania, California, Texas, New York, Washington, Indiana, Wisconsin, Minnesota, and Nebraska. The UK foundations were located mostly in London, apart from 5 that were located in other parts of England, i.e. Preston, Birmingham, Coventry, Essex, Worcester, 2 in other parts of Britain and Europe: Scotland and Switzerland. German foundations were located in diverse regions of the country with no overlap among the location of the headquarters. ${ }^{3}$ The foundations in Japan were also concentrated in the capital, Tokyo, with 5 exceptions: Kagoshima, Nagasaki, Kyoto, and Osaka. The private foundations analyzed were almost entirely single-nation enterprizes. We used the term "headquarters", predicated upon the idea that the foundation would have a head office in one city or nation and would have branch offices in other parts of the country or the world. However, no other foundation in 
our sample apart from the Gates Foundation and Japan's Interchange Association had an incorporated presence in another country. Notably, the Gates Foundation has recently (as of 2009) opened a branch office in London, preceded by those in Washington D.C., New Delhi and Beijing (Heim, 2009).

The distributions of foundation headquarters in each country reflect the country's corporate geography. If we were to take the Forbes 100 corporations in market capitalization, the headquarters of the British and Japanese firms would likely be located in the respective capitals, whereas the American and German counterparts would be more evenly distributed throughout the respective countries, corresponding to the more balanced urban hierarchy of each country (Coe et al., 2007) (Clark et al., 2003). The finding that the foundations are mostly single-nation enterprise is striking when we consider that some of the foundations do carry out international work, e.g. Gates Foundation in developing countries or some other organizations in the countries that do not have the religious tradition that the foundations support as being the official state religion.

Furthermore, the 80 foundations under consideration represent some of the wealthiest organizations in each country, for-profit or otherwise, with average assets ranging from $\$ 105$ million to $\$ 65$ billion per country. Even some of the best-endowed US foundations are at best bi-coastal, i.e. Gates Foundation has offices in Seattle, Washington and the East Coast (DC) and Annenberg Foundation in LA, California and Radnor, Pennsylvania. This is in sharp contrast to the for-profit practice, where even small-to-medium sized startups with assets of several thousand dollars often have branch offices in various parts of the world (Clark et al., 2003). In addition, some of the foundations make it explicit in their mission statements that they demand measurable outcomes (Hewlett, 2009) (Gates, 2009). Combined with the fact that the same foundations carry out offshore projects, it would seem reasonable that they would require staff on the ground so as to monitor and evaluate the progress of their projects. The absence of international or domestic branches seems to contradict their commitments, either in administering on-the-ground due diligence or coordinating with local partners. This clearly indicates that a different cultural norm and mindset are at work when it comes to private foundations.

5.4. Areas of Giving. The areas to which the foundations give reflect the values that the foundations have and also the roles that they see themselves as playing in service to such values. The Anglo-American foundations gave to diverse range of areas that would commonly be associated with philanthropy, e.g. health care, education, international development, supporting the arts (Fleishman, 2007). The Japanese foundations were much more specific with many of their missions indicated in the names of the foundations themselves, e.g. scholarship association or foundations or ikueikai. The areas of funding reveal much about the role of the philanthropic foundation in each country. The Anglo-American foundations, to a large extent, took on the role of addressing social needs that have not been met either by the market or the government initiatives, particularly areas such as environmental conservation, liberal arts, public television, and causes that are tied to specific religions such as Judaism. The German and Japanese private foundations, on the other hand, seemed to play a smaller role by supporting more narrowly-defined areas. Evidence suggests that this limitation is particularly pronounced in Japan, where the areas of support were rather restricted to funding scholarly activities and a handful of somewhat unusual areas of support for philanthropic foundations such as horse racing welfare and venture enterprise.

5.5. Geographic Focus of Giving. Although some of the larger US foundations such as the Gates and Buffett foundations supported causes abroad, most foundations were 
committed to their local communities, some of them explicitly stating their missions in serving the surrounding exclusively, e.g. San Francisco Bay Area, Texas, and Indiana. The UK foundations on the whole did not specify their geographical focus, but they tended to support causes within the UK. Notable exceptions included a foundation focusing on countries abroad that had relatively smaller presence of the Christian faith; other geographic foci included Coventry, Essex, and Scotland. The German foundations supported activities that are primarily within Germany; when they did support other countries, they specified the countries such as Israel, Turkey, Bulgaria, or regions such as Central and Eastern Europe. The Japanese foundations' geographic focus was the most restrictive out of the group of countries, i.e., exclusively within Japan. In addition, their intended beneficiaries were restricted to Japanese students, Japanese subjects abroad, and in the case of foreign subjects, those who are residing or studying in Japan. In short, the US foundations served primarily their local (broadly defined as being inclusive of their immediate surroundings such as the home city or state) communities, the UK foundations mostly the UK, the German foundations somewhat more diverse areas such as their cities, Länder, and neighboring countries, and the Japanese foundations almost exclusively Japan.

The fact that the foundations are committed to serving their local communities supports the thesis that philanthropy is a highly personal and value-driven activity (Jones and Dawson, 2007). Entrepreneurs who not only grow up in specific geographic regions but also accumulate their wealth in the regions are likely to feel that they owe it to their community to contribute to their local causes. As we observed earlier, it is entrepreneurs that are frequently those that set up their own private foundations. Combining the two, it is logically consistent that the foundations would be committed to supporting the local causes and communities. Another important aspect to note is the fact that there are overlaps in projects and the geographic foci, i.e. many of the 80 foundations considered herein pursue projects that are similar in nature and serve similar geographic areas, e.g. health research, education, visual and performing arts, and environmental conversation in their local communities. This implies that a meaningful comparison or even competition amongst the foundations, centering around specific projects, is indeed possible.

5.6. Sources of Income and Asset Management Policies. The US private foundations, as indicated by the $990-\mathrm{PF}$ form ${ }^{4}$ generated their income from a variety of sources: donations, interest on savings, dividends and interest from securities, rental income, and sale of assets. In contrast to the Anglo-American models, the German foundations stated that their income stemmed primarily from stock ownership of the 'mother companies'. When it comes to the Japanese foundations, by the virtue of the fact that they are primarily community and corporate foundations, their sources of income stemmed almost exclusively from the community and corporation that founded them.

The private foundations in the four industrialized countries differed in asset-management policies as well. It is easy to disregard the fact that most of the foundations under consideration in the current study manage billions of US dollars or the equivalent thereof. They can make the money go idle or invest them actively. To this end, several larger US foundations, including the Gates, Moore and Packard Foundations, had dedicated teams that manage their asset, investing them in various asset vehicles. When it comes to the UK foundations, 12 private foundations out of 20 explicitly stated that their income stemmed from investment activities. None of the German or Japanese foundations had explicit statements about such policies, implying that they do not actively engage in outsourcing the management of their assets to professional money managers. We observe an intriguing parallel in the level of supply in specialized asset management service providers in each 
country. The Anglo-American financial services industry has witnessed an increasing number of such firms (Clark and Wojcik, 2007), i.e. firms that provide services whereby they would allocate assets on behalf of their clients, such as mutual funds, venture capital firms, hedge funds, and private equity funds. In German and Japanese financial services industries, such specialized firms are much less common in comparison (Martin, 1999). In other words, the method by which the foundations generate their incomes as well as how they manage their assets reflect the structure of the financial services sector in each country.

5.7. Methods of Giving. Both the US and the UK foundations favored awarding grants to other non-profit organizations. Many US foundations specified that their beneficiaries would need to be registered "501(c)(3)" entities. ${ }^{5}$ Virtually all of the British foundations in the current study explicitly stated giving grants to "other charities" as being their method of choice regarding funding. A striking feature of the German foundations was that most of them tended to pursue their own initiatives and projects rather than giving grants to other non-profits. For example, Bertelsmann, as a matter of policy, exclusively funds their own initiatives (Bertelsmann, 2006). ${ }^{6}$ The Japanese foundations held a similar practice, where they primarily own initiatives, and when they 'entrusted' their grants to other organizations, it was in the form of awarding scholarships.

When it came to the method of generating income, the Anglo-American private foundations preferred to 'outsource' their activities to the dedicated asset management firms, while the German and Japanese foundations relied on stock dividends of their parent companies or direct voluntary donations. Similarly, when it came to deploying their capital, the two pairs of countries differed in execution. The Anglo-American private foundations, in effect, 'outsourced' their charitable activity to the organizations, the expertise and dedicated activities of which are in working 'in the field', while the German and Japanese foundations kept direct control over their projects. In other words, the foundations of the former pair of countries had a more 'compartmentalized' or 'outsourced' approach to both asset creation and deployment, whereas the counterpart of the latter pair had a more 'controlled' or 'hands on' approach. These variations in income generation and asset deployment resonate with the ways in which the Anglo-American capitalism and the German and Japanese capitalism differ, i.e. open and closed corporate governance regimes, respectively (Clark and Wojcik, 2007) (Martin, 1999). This observation informs a potential theoretical framework that might be termed "varieties of philanthropy", reflecting the "varieties of capitalism" tradition (Hall and Soskice, 2001).

5.8. Performance Measurement. Having considered how the foundations generate income, what, where, whom, and how they give, it is appropriate to ask how they monitor and evaluate the effectiveness of the projects that they fund. In this respect, the commitment to measuring performance on the part of the foundations in our sample was relatively sporadically mentioned. That being stated, the Anglo-American foundations showed greater commitment relative to the German and Japanese counterparts; for example, the Gates Foundation, the Hewlett Foundation, and the Wellcome Trust explicitly stated that they sought "measurable results". In the UK, the Charity Commission document Summary Information Return 2008 of Aims, Activities and Achievements asked each foundation a series of 7 questions. ${ }^{7}$ One of the questions pertains to performance measure: "How does your charity measure the success of the strategy?" The responses from the foundations were diverse, depending on how the foundation interpreted the question. Responses included the statement that they had programs for "monitoring and evaluation" such as "ten indicators of progress", "ability to continue funding beneficiaries", and "not applicable". Other responses included site visits, annual review, comments, and meetings, albeit no further 
mention of any specifics of such activities. In other words, what counts as "performance measurement" even in the Anglo-American context is still subject to interpretation. There was no specific mention of monitoring or evaluation of effectiveness of strategies in neither the German nor the Japanese foundations in our sample. ${ }^{8}$

The above reveals, on the one hand, that the private foundations do not have a universal emphasis on the centrality of performance measure as a part of their activities, contrary to the corporate sector. On the other hand, those that did emphasize it were mostly AngloAmerican foundations, mirroring the fact that Anglo-American corporate governance is more 'open' and that it, too, puts greater emphasis on transparent reporting of performance metrics. It is particularly interesting to note that the so-called "venture philanthropy", which presumably borrows from the monitoring and evaluation practices of the venture capital industry, is a uniquely Anglo-American phenomenon, which in turn is particularly prevalent in the Anglo-American capitalism. In other words, while the philanthropy sector tends to be less transparent in the usage and reporting of performance measurements compared to the corporate sector, the culture of performance measurement and reporting in the corporate sector carries over to the philanthropic sector.

\section{Conclusions And Implications}

Our objective in this paper was to lay the groundwork for a theory of private foundation governance, mirroring corporate finance, by exploring philanthropic finance. We sought to do this through a comparative analysis of the sizes and structures of private foundation giving in the year 2005 by the 20 highest-giving foundations in the US, the UK, Germany, and Japan, relying on certain select features. We approached the subject matter from the economic geographer's perspective, gathering data from a variety of sources and drawing insights from both economic geography and geography of finance, particularly the notions of the economy being a socio-cultural complex rather than an ethereal and monolithic entity, there being varieties of states and the corporate cultures being embedded in national cultures of their origin, and drawing 'bottom up' conclusions.

In regard to the sizes of philanthropic finance per country, we found that the levels of national and individual wealth and taxation were not reliable predictors for the level of private foundation giving as might have been expected. For example, while the UK and Japan had similar income tax regimes for the top-bracket earners, the levels of philanthropic giving varied widely. Instead, socio-cultural factors such as the perceptions about wealth inequality, civic voluntarism, deference to the state, and the attitude towards religion were revealed to be more relevant.

In regard to the structures of philanthropic finance, we observed significant similarities and differences amongst the 80 foundations in our sample. In regard to the similarities, firstly, most foundations were founded in years which were not very dissimilar from each other; what we observe as contemporary philanthropy is mostly a path-dependent product of the post-WWII wealth accumulation by the young entrepreneurs of the era. Secondly, virtually none of even the wealthiest foundations in all four countries had 'multinational' presence, even those that have projects that are actively on-going in offshore locations. Thirdly, most foundations served their 'local' communities, whether it be their home cities, greater metropolitan areas, states or Länder, or countries as a whole. Fourthly, there is a general absence or lack of emphasis on performance measurement as being a vital component of their activities. This is clearly distinct from the corporate culture worldwide. To put it simply, if we were to consider top 20 corporations in terms of market capitalization, for example, they would almost certainly exhibit a wide spread in founding years, locations 
of their headquarters, and the geographic regions in which they operate. Moreover, they would certainly emphasize their "bottom line" and other metrics to be reported.

The most distinct differences amongst the foundations according to their nationalities were in the methods for generating income, managing assets, and deploying the capital. The Anglo-American foundations drew their incomes through a variety of channels, whilst the German and Japanese foundations were restricted in their sources. Regarding asset management policies as well as methods of giving, the Anglo-American foundations were far more prone to 'outsource' their asset management to third-party asset management service providers and other registered charities, whereas the German and Japanese foundations did not specify explicit policies in regard to asset management and pursued primarily their own projects. Interestingly, these national variations reflect those in the corporate governance and the state of the financial services industry. Also, while most foundations did not explicitly specify methodologies for monitoring and evaluating the effectiveness of their strategies, some of the larger Anglo-American foundations stated that they expect measurable results and that they utilize specific systems for "monitoring and evaluation" (or "M\&E"), while there was a call for greater transparency in M\&E on the part of the German and Japanese foundations. Strikingly, as the so-called the "German model" of corporate governance is increasingly assimilating some features of the Anglo-American counterpart (Clark and Wojcik, 2007), so seem to be the German and Japanese foundations increasingly influenced by the Anglo-American counterparts, particularly with respect to transparency, of which performance measurement is a crucial element.

Our exploratory research addresses gaps in the literature in regard to the theory of private foundation governance, and in a larger sense, 'philanthropic culture'. That is, on the one hand, the philanthropy sector of a country has its own culture that is distinct from the corporate culture of the nation; yet on the other hand, the corporate culture of a country in forms the philanthropic culture of the country so as to systematically distinguish it from the philanthropic culture of another country. ${ }^{9}$ How the philanthropic culture differs from the corporate culture pertains, largely, to values and ethos: why an individual might be motivated to contribute towards a personally meaningful cause in his or her local community through monetary means, e.g. by setting up a private foundation. How the corporate culture of a nation informs the philanthropic culture reflects more the methodological and the practical, i.e. the method by which such an organization would manage their asset and deploy capital. It was particularly interesting to note that performance measurement features in both instances: it was absent in the philanthropic sectors of all four countries compared to their respective corporate sectors, but the US and the UK foundations put greater emphasis, albeit embryonic, on performance measurement. Crucially, the US and the UK corporate governance and organization generate well-developed reporting schemes as a byproduct. These results are preliminary and exploratory, paving the way for a more systematic study on foundation governance and larger topics that put it in the appropriate theoretical context.

Our results have implications pertaining to the viability of competition amongst private foundations. It has often been claimed that due to the nature of the projects e.g. diversity, intangibility, and people-orientation, that private foundations (and non-profit and charity organizations as a whole) cannot be compared with each other via quantitative metrics (Bishop and Green, 2008) (Brest and Harvey, 2008). However, we have found that private foundations overlap to a significant extent both in terms of project areas and geographic focus. In other words, many of them pursue similar projects in similar geographic areas. This finding suggests that we need to look beyond the non-profit rhetoric and consider pragmatic ways in which private foundations could compete and collaborate; 
it also implies that performance metrics are not only feasible but can be put to good use in fostering such activities.

\section{ACKNOWLEDGMENT}

The authors would like to thank the many institutions and individuals that made this research possible, particularly Dr. Walter Hewlett of the Hewlett Foundation for valuable insights. None of the above should be held responsible for any errors or omissions expressed herein.

\section{Notes}

${ }^{1}$ In particular, there is a conspicuous absence of the likes of the foundations set up by some of the "captains of industry" such as Andrew Carnegie and John D. Rockefeller, which would have significantly increased the average age of the foundations. This is probably due to the fact that Andrew Carnegie made an explicit goal of donating most, if not all, of his money in his lifetime (Lagemann, 1989), and John D. Rockefeller (Berman, 1983) followed suit.

${ }^{2}$ Interestingly, contrary to what might have been expected, the US founders were not greatly more religious than the British counterparts.

${ }^{3}$ Interestingly, in Bavaria, the Land that is considered to be the wealthiest in the country, there is no representation of private foundations.

4 The IRS Form 990 "Return of Organization Exempt from Income Tax" is a form issued by the Internal Revenue Service, the US tax administration agency, which every non-profit organization has to complete and report. The 990-PF form is the version that is issued to private foundations. It includes items such as revenue and expenses breakdown, balance sheets, capital gains and losses for tax on investment income, and so on.

${ }^{5}$ 501(c) is a provision of the United States Internal Revenue Code (26 U.S.C. section 501(c)), listing 26 types of non-profit organizations that are exempt from some federal income taxes; many states reference Section 501(c) for definitions of organizations exempt from state taxation as well.

6 This is not to say that no exceptions exist. Bertelsmann both funded a conference on 'nonprofit analysis' in London in May 2009 and has awarded a grant to a London-based charity consulting firm. Such an activity, however, is more of an exception than the norm.

7 The document stipulates, "This return is intended to comprise a Summary of key information contained in the Trustees' Annual Report and Accounts and in other documents". Out of the 20 foundations in question, 18 foundations completed the questionnaire and returned it.

${ }^{8}$ While the absence of mention does not equate with the absence of practice, there are evidences to suggest that the latter might be the case: for example, Bertelsmann Stiftung in Germany is launching an initiative to create an organization dedicated to measuring the impact of charitable organizations in Germany, benchmarking a UK organization, precisely to address such a gap (Bertelsmann, 2009).

${ }^{9}$ Consider the following analogy: if an American, British, German and Japanese individual were to learn a foreign language, e.g. Spanish, they would each acquire a language that is clearly distinct from their native tongue, yet at the same time the 'Spanish' spoken by each person will not be identical but distinct from each other, by the 'accent' that is informed by his or her native language.

\section{REFERENCES}

Anderson, T. A. (2005). Part gift and part sale: Can you have your cake and eat it too? Journal of Taxation of Investments, 24:29-38.

Andreoni, J. and McGuire, M. C. (1993). Identifying the free riders: A simple algorithm for determining who will contribute to a public good. Journal of Public Economics, $51(3): 447-454$. 
Apinunmahakul, A. and Devlin, R. A. (2008). Social networks and private philanthropy. Journal of Public Economics, 92(1-2):309 - 328.

Atkinson, A. B. (2008). The changing distribution of earnings in OECD countries. Oxford: Oxford University Press, Oxford.

Atkinson, A. B. and Piketty, T. (2007). Top incomes over the twentieth century: a contrast between continental European and English-speaking countries. Oxford: Oxford University Press, Oxford.

Berger, I. (2006). The influence of religion on philanthropy in canada. Voluntas: International Journal of Voluntary and Nonprofit Organizations, 17:110-127.

Berghahn, V. R. (1999). Philanthropy and diplomacy in the "american century". Diplomatic History, 23(3):393-419.

Berman, E. H. (1983). Influence of the Carnegie, Ford and Rockefeller Foundations on American Foreign Policy: The Ideology of Philanthropy. State University of New York Press.

Bertelsmann (2006). Effectiveness, efficiency and accountability in philanthropy: what lessons can be learned from the corporate world. Bertlesmann Stiftung, Gutersloh.

Bertelsmann (2009). Bertelsmann foundation website.

Bishop, M. (2006). Billanthropy. Economist.

Bishop, M. and Green, M. (2008). Philanthrocapitalism. Bloombury Press.

Blumkin, T. and Sadka, E. (2007). A case for taxing charitable donations. Journal of Public Economics, 91(7-8):1555 - 1564.

Brest, P. and Harvey, H. (2008). Money Well Spent: A Strategic Guide to Smart Philanthropy. Bloomberg Press.

Brown, C. S. (2005). Sustainable Enterprise: Profiting from Best Practice. Kogan Page, illustrated edition edition.

Browne, R. B. (2003). Angels in the american theater: Patrons, patronage, and philanthropy edited with an introduction by robert a. schanke. The Journal of American Culture, 30:334-335.

Buckley, E. and Croson, R. (2006). Income and wealth heterogeneity in the voluntary provision of linear public goods. Journal of Public Economics, 90(4-5):935 - 955.

Buckley, S. (2001). Encyclopedia of Contemporary Japanese Culture (Encyclopedias of Contemporaryculture). Routledge.

CAF (2009). International comparisons of charitable giving. Individual giving in select countries including South Africa.

Caiger, J. G. (1997). A History of Japan: Revised Edition. Tuttle Publishing, revised edition.

Castro, M. F. (2008). Where are you from? cultural differences in public good experiments. Journal of Socio-Economics, 37(6):2319 - 2329. Special Issue: Cooperatives and the Economy.

CC (2009). Charity commission website. www.charity-commission.gov.uk.

Christensen, K. and Levinson, D. (2003). The Encyclopedia of Community: from the Village to the Virtual World. Berkshire Publishing Group.

Cizakca, M. (2000). A History of Philanthropic Foundations: The Islamic World From the Seventh Century to the Present. Bogazici University.

Clark, G. L., Dixon, A. D., and Monk, A. H. B. (2009). Managing Financial Risks: From Global to Local. Oxford University.

Clark, G. L., Gertler, M. S., and Feldman, M. P. (2003). The Oxford Handbook of Economic Geography (Oxford Handbooks). Oxford University.

Clark, G. L. and Wojcik, D. (2007). The Geography of Finance: Corporate Governance in a Global Marketplace. Oxford University. 
Coe, N. M., Kelly, P. F., and Yeung, H. W.-C. (2007). Economic geography: a contemporary introduction. Blackwell, Oxford.

CoP (2009). The chronicle of philanthropy.

Corbridge, S., Thrift, N. J., and Martin, R. (1994). Money, Power and Space. Blackwell Publishers.

Diamond, P. (2006). Optimal tax treatment of private contributions for public goods with and without warm glow preferences. Journal of Public Economics, 90(4-5):897 - 919.

Dimson, W. W. . E. (2007). European foundations: Report on top 50 ranking and database. Joint research project by Watson Wyatt \& Prof. Elroy Dimson of LBS. Contains 50 largest private/community/corporate foundations and country breakdown, investment portfolio etc.

Dore, R. P. (2000). Stock Market Capitalism: Welfare Capitalism. Japan and Germany versus the Anglo-Saxons. Oxford University Press.

Dowie, M. (2002). American Foundations: An Investigative History. The MIT Press.

EFC (2005). Foundations assets in eu countries. Research Task Force.

EFC (2008a). Comparative highlights of foundation laws.

EFC (2008b). Comparative map of the foundation sector in the eu. Geographic overview, including variations in definitation, asset allocation.

EFC (2009). European foundation centre website.

Fleishman, J. (2007). Casebook for The Foundation: A Great American Secret. PublicAffairs.

Flynn, P. (2002). Measuring the Impact of the Nonprofit Sector (Nonprofit and Civil Society Studies). Springer, first edition.

FT (2009a). Financial times.

FT (2009b). Financial times philanthropy section.

Gates (2009). The bill and melinda gates foundation website. http://www.gatesfoundation.org.

Gaudiani, C. (2003). The Greater Good: How Philanthropy Drives the American Economy and Can Save Capitalism, volume 1st. Times Books/Henry Holt, New York.

Glaeser, E. L. and Shleifer, A. (2001). Not-for-profit entrepreneurs. Journal of Public Economics, 81(1):99 - 115 .

Grimm, R. T. (2002). Notable American Philanthropists: Biographies of Giving and Volunteering. Greenwood Press.

Gruber, J. and Hungerman, D. M. (2007). Faith-based charity and crowd-out during the great depression. Journal of Public Economics, 91(5-6):1043 - 1069.

Guiso, L. (2009). Does culture affect economic outcomes? Journal of Economic Perspectives, 20(2):23-48.

Hall, P. A. and Soskice, D. W. (2001). Varieties of capitalism: the institutional foundations of comparative advantage. Oxford University Press, Oxford.

Harbaugh, W. T. (1998). What do donations buy?: A model of philanthropy based on prestige and warm glow. Journal of Public Economics, 67(2):269 - 284.

Hasan, S. (2008). Comparative Third Sector Governance in Asia: Structure, Process, and Political Economy (Nonprofit and Civil Society Studies). Springer, first edition.

Heim, K. (2009). Gates foundation opening london office. Seattle Times.

Hewlett (2009). The william and flora hewlett foundation website.

Hofstede (2009). Geert hofstede cultural dimensions.

Hurd, H., Mason, C., and Pinch, S. (1998). The geography of corporate philanthropy in the united kingdom. Environment and Planning C: Government and Policy, 16(1):3-24.

Ilchman, W. F. (1998). Philanthropy in the World's Traditions (Philanthropic and Nonprofit Studies). Indiana University Press. 
JFC (2009). Japanese foundations assets and giving. Top 20 private and public foundations composite. Static website rather than an actual publication.

Jones, P. and Dawson, P. (2007). [']choice' in collective decision-making processes: Instrumental or expressive approval? Journal of Socio-Economics, 36(1):102 - 117. Essays on Behavioral Economics.

Karlan, D. and List, J. A. (2006). Does price matter in charitable giving? evidence from a large-scale natural field experiment.

Kolm, S.-C. and Ythier, J. M. (2006). Handbook of the Economics of Giving, Altruism and Reciprocity, Volume 2: Applications (Handbooks in Economics). North Holland, first edition.

Kumar, K. and Thibodeaux, M. S. (1998). Differences in value systems of anglo-american and far eastern students: Effects of american business education. Journal of Business Ethics, 17(3):253-262.

Lagemann, E. C. (1989). The politics of knowledge: the Carnegie Corporation, philanthropy, and public policy. Wesleyan University Press, Middletown, Conn.

Lakdawalla, D. and Philipson, T. (2006). The nonprofit sector and industry performance. Journal of Public Economics, 90(8-9):1681 - 1698.

Laroche, M. (2009). Impact of culture on marketing strategy: Introduction to the special issue. Journal of Business Research, 62(10):921 - 923. Impact of Culture on Marketing Strategy.

Leyshon, A. (1997). Money/Space: Geographies of Monetary Transformation (International Library of Sociology). Routledge, first edition.

Martin, R. (1999). Money and the space economy. John Wiley, Chichester.

McCleary, R. M. and Barro, R. J. (2006). U.s.-based private voluntary organizations: Religious and secular pvos engaged in international relief \& development.

Micklethwait, J. and Wooldridge, A. (2003). The Company: A Short History of a Revolutionary Idea. Weidenfeld \& Nicolson.

Onishi, T. Japanese fundraising: A comparative study of the united states and japan. International Journal of Educational Advancement, 7:205-225.

Payton, R. L. (2008). Understanding Philanthropy: Its Meaning and Mission (Philanthropic and Nonprofit Studies). Indiana University Press.

Pharoah, C. (2008). Family foundation philanthropy: Report on the giving of the largest charitable family foundations in the us, the uk, and the rest of europe 2008.

Porter, M. and Kramer, M. (1999). Philanthropys new agenda: Creating value. Harvard Business Review.

Powell, W. W. (2006). The Nonprofit Sector: A Research Handbook, Second Edition. Yale University Press, second edition.

Prewitt, K. (2006). The Legitimacy of Philanthropic Foundations: United States and European Perspectives. Russell Sage Foundation Publications.

Raymond, S. U. and Martin, M. B. (2007). Mapping the new world of American philanthropy: causes and consequences of the transfer of wealth. John Wiley \& Sons, Hoboken, N.J.

Ross, A. D. (1953). The social control of philanthropy. The American Journal of Sociology, 58(5):451-460.

Sheppard, E. and Barnes, T. J. (2002). A companion to economic geography. Blackwell Science.

Tadashi, Y. (1999). Deciding the Public Good: Governance and Civil Society in Japan. Japan Center for International Exchange.

Til, J. V. (2008). Searching for critical issues in philanthropy. Nonprofit Management and Leadership, 19(1):123-128. Book review. 
Trommsdorff, G. (1985). Some comparative aspects of socialization in japan and germany. von Kotzebue, A. and Wigger, B. U. (2009). Private contributions to collective concerns: modelling donor behaviour. Camb. J. Econ., page bep003.

Whitman, J. R. (2009). Philanthropy and accountability in europe. Nonprofit Management and Leadership, 19(3):405-410.

Wolpert, J. (Dec., 1988). The geography of generosity: Metropolitan disparities in donations and support for amenities. Annals of the Association of American Geographers, 78(4):665-679.

WVS (2009). The world values survey.

St. Catherine's College, Oxford, OX1 3UJ, United Kingdom

E-mail address: steve.lew@ouce.ox.ac.uk 
TABLE 2. Selected Features of Top 20 Foundations According to Giving by Country. (Source: authors' compilations based on data from the Foundation Center, Charity Commission, European Foundation Centre, individual websites of the foundations, and annual reports.)

\begin{tabular}{|c|c|c|c|c|}
\hline Variable & $\overline{\mathrm{US}}$ & UK & Germany & Japan \\
\hline Avg Founding & 1962.0 & 1969.3 & 1974.8 & 1973.0 \\
\hline Year & & & & \\
\hline Avg Age & 46.94 & 37.95 & 34.20 & 36.00 \\
\hline Med Age & 55.00 & 43.00 & 35.00 & 36.00 \\
\hline $\begin{array}{l}\text { Founder's } \\
\text { Background }\end{array}$ & Diverse $\square^{a}$ & Diverse $]^{b}$ & Diverse $[9$ & Restrictive [d \\
\hline Founder's Re- & Some mention: & Some mention: & Secular & Secular \\
\hline ligiosity & $\begin{array}{l}\text { Christian and } \\
\text { Jewish }\end{array}$ & $\begin{array}{l}\text { Christian and } \\
\text { Jewish }\end{array}$ & & \\
\hline $\begin{array}{l}\text { Founder's } \\
\text { Origin }\end{array}$ & Mostly USA & Mostly UK & Germany only & Japan only \\
\hline HQ Location & $\begin{array}{l}\text { Mostly bi- } \\
\text { coastal }\end{array}$ & Mostly London & $\begin{array}{l}\text { Throughout } \\
\text { Germany }\end{array}$ & Mostly Tokyo \\
\hline $\begin{array}{l}\text { Areas of Giv- } \\
\text { ing }\end{array}$ & $\begin{array}{l}\text { Diverse and dis- } \\
\text { cretionary }\end{array}$ & $\begin{array}{l}\text { Diverse and dis- } \\
\text { cretionaryf }\end{array}$ & $\begin{array}{l}\text { Somewhat more } \\
\text { specific and dis- } \\
\text { cretionary } g^{g}\end{array}$ & $\begin{array}{l}\text { Limited and re- } \\
\text { strictive }{ }^{h}\end{array}$ \\
\hline $\begin{array}{l}\text { Geographic } \\
\text { Focus of } \\
\text { Giving }\end{array}$ & Mostly local & Mostly national & $\begin{array}{l}\text { Mostly national } \\
\text { and some inter- } \\
\text { national }{ }^{j}\end{array}$ & Mostly national \\
\hline $\begin{array}{l}\text { Income } \\
\text { Sources }\end{array}$ & Varied & $\begin{array}{l}\text { Mostly invest- } \\
\text { ment income }\end{array}$ & $\begin{array}{ll}\text { Mostly } & \text { stock } \\
\text { dividends } & \end{array}$ & Mostly donation \\
\hline $\begin{array}{l}\text { Investment } \\
\text { Policies }\end{array}$ & $\begin{array}{l}\text { 3rd-party asset } \\
\text { managers }\end{array}$ & $\begin{array}{l}\text { 3rd-party asset } \\
\text { managers }\end{array}$ & No mention & No mention \\
\hline $\begin{array}{l}\text { Method of } \\
\text { Giving }\end{array}$ & $\begin{array}{l}\text { Mostly grants to } \\
501(\mathrm{c})(3) \text { 's }\end{array}$ & $\begin{array}{l}\text { Grants to other } \\
\text { registered chari- } \\
\text { ties }\end{array}$ & $\begin{array}{ll}\text { Mostly } & \text { own } \\
\text { projects } & \end{array}$ & $\begin{array}{ll}\text { Mostly } & \text { own } \\
\text { projects } & \end{array}$ \\
\hline $\begin{array}{l}\text { Performance } \\
\text { Measurement }\end{array}$ & $\begin{array}{l}\text { Sporadic men- } \\
\text { tion; Gates and } \\
\text { CA foundations } \\
\text { more vocal }\end{array}$ & $\begin{array}{ll}\text { Charity } & \text { Com- } \\
\text { mission } & \text { ques- } \\
\text { tionnaire, } & \text { ques- } \\
\text { tion no. } 3 . & \\
\end{array}$ & No mention & No mention \\
\hline
\end{tabular}

${ }^{a}$ ICT, oil, finance, insurance, chemical

${ }^{b}$ Retail, finance, publishing, automobile, inheritance

${ }^{c}$ Engineering, pharmaceutical, publishing, retail, heavy industries, ICT, tobacco

${ }^{d}$ Private club of businessmen, gov. ministries, local governments, conglomerates, finance, motors

${ }^{e}$ Health care and research, global development, education, religion, arts and science research, environmental conservation, public broadcasting, visual and performing arts

${ }^{f}$ Medical research, support to Africa, education, arts, social justice, human rights, Christian evangelism, housing for the poor, poverty alleviation

${ }^{g}$ Biomedical research, law school, journalism, neuroscience, olympics, young talents, music prize

$h$ Scholarships to secondary schools and universities, horse racing welfare, environmental conservation, fostering entrepreneurship

$i$ 'Local' in the US terms is rather broad, including home cities, surrounding metropolitan areas, and home states

${ }^{j}$ Throughout Germany and surrounding countries in Central and Eastern Europe 